\title{
Expression of galectin-3 in gonads and gonadal sex cord stromal and germ cell tumors
}

\author{
MOJGAN DEVOUASSOUX-SHISHEBORAN ${ }^{1,2}$, CATHERINE DESCHILDRE $^{1}$, CLAIRE MAUDUIT $^{1}$, \\ GÉRARD BERGER ${ }^{3}$, FRÉDÉRIQUE MEJEAN-LEBRETON ${ }^{2}$, RAYMONDE BOUVIER ${ }^{3}$, \\ JEAN PIERRE DROZ $^{1}$, PATRICK FÉNICHEL ${ }^{4}$ and MOHAMED BENAHMED ${ }^{1}$ \\ ${ }^{1}$ Unité INSERM 407, Lyon, F-69921; ${ }^{2}$ Department of Pathology, Hôpital de la Croix Rousse, 103 Grande rue de \\ la Croix Rousse, 69317 Lyon Cedex 04; ${ }^{3}$ Department of Pathology, Hôpital Edouard Herriot, place \\ d'Arsonval, 69437 Lyon Cedex 03; ${ }^{4}$ Department of endocrinology and medicine of \\ reproduction CHU Nice, BP 3079, F06202 Nice Cedex, France
}

Received December 19, 2005; Accepted March 22, 2006

\begin{abstract}
Galectin-3, a ß-galactoside-binding lectin, has been implicated in many human malignancies, but has seldom been studied in human gonads and gonadal tumors. The aim of our study was to investigate galectin-3 mRNA and protein expression in normal ovaries and testes as well as in a variety of 51 gonadal sex cord stromal and germ cell tumors, and two testicular seminomatous and non-seminomatous cell lines, using either real-time PCR or immunohistochemistry. In human testes, galectin-3 is specifically expressed in mature Sertoli cells and Leydig cells, and is absent from fetal and prepubertal testes, suggesting a hormone-dependence of this gene. In human ovaries, galectin-3 is absent from granulosa cells, as well as from granulosa cell and Sertoli-Leydig cell tumors, and is not a useful marker in distinguishing granulosa cell from Sertoli-Leydig cell tumors. In testicular tumorigenesis, galectin-3 has a dual function according to the histological type of tumors and their hormone dependency. In malignant testicular Sertoli cell tumors, the expression of galectin-3 is down-regulated while, in benign Leydig cell tumors, this expression is maintained, indicating the possible implication of this gene in the development of more aggressive testicular sex cord stromal tumors. In contrast to sex cord stromal tumors, galectin-3 expression is up-regulated in testicular germ cell tumors. By real-time PCR, we demonstrated a significant elevation of the galectin-3 mRNA level in non-seminomatous testicular germ cell tumors and cell line as compared to normal testes and seminomas
\end{abstract}

Correspondence to: Dr Mohamed Benahmed, Institut National de la Santé et de la Recherche Médicale (INSERM Unité 407), Faculté de Médecine Lyon Sud, BP12, 69921 Oullins Cedex, France

E-mail: benahmed@grisn.univ-lyon1.fr

Key words: testis, sex cord tumors, germ cell tumors, galectin, lectins, galectin-3
( $\mathrm{p}=0.0432$ and $\mathrm{p}=0.0247$, respectively), indicating the possible role of this gene in the non-seminomatous differentiation of germ cell tumors.

\section{Introduction}

Galectin-3 is a member of the B-galactoside-binding lectins. This protein is expressed in a variety of tissues and plays a role in diverse biological events, such as embryogenesis, angiogenesis, adhesion, cellular proliferation, apoptosis, and modulation of the inflammatory process and immune response (1). Galectin-3 has also been implicated in tumor progression and metastasis in a variety of human cancers such as thyroid, pancreas, colonic and breast carcinomas (2-4). While its role in the testes and testicular tumors has been seldom studied $(5,6)$, it remains not well characterized.

Testicular tumors are subdivided into several categories including germ cell tumors and sex cord gonadal stromal tumors. Germ cell tumors are classified into seminomas and non-seminomas. Non-seminomas are more aggressive neoplasms than seminomas, with a higher rate of distant metastasis. The molecular basis of germ cell tumorigenesis and the aggressive clinical behavior of non-seminomas remain unknown. Sex cord gonadal stromal tumors are rare, accounting for $4 \%$ of testicular and $8 \%$ of ovarian neoplasms. They are subdivided into Sertoli cell, granulosa cell, and Leydig cell tumors, arising in both male and female gonads. The immunophenotype of Sertoli cell tumors is almost identical to that of granulosa cell tumors with expression of inhibin and lack of EMA (epithelial membrane antigen) (7). In some poorly or undifferentiated cases, the distinction between granulosa cell and Sertoli cell tumors may be impossible. There is no available diagnostic immunohistochemical marker of Sertoli or granulosa cell differentiation. Approximately $20 \%$ of ovarian Sertoli-Leydig cell tumors and $12 \%$ of testicular Sertoli cell tumors have a malignant behavior and develop metastases. The molecular mechanism of tumorigenesis and tumor progression in this very rare category of tumor is unknown.

The aim of this study was to evaluate the expression of galectin-3 in human gonads (testis and ovary) and in sex cord 
Table I. Histological types and staging of testicular and ovarian tumors.

\begin{tabular}{|c|c|c|c|c|}
\hline & Ovary & Stage $^{b}$ & Testis & Stage $^{\mathrm{a}}$ \\
\hline \multicolumn{5}{|l|}{ Germ cell tumors } \\
\hline Seminoma & $\mathrm{N}=0$ & & $\mathrm{~N}=13^{\mathrm{c}}$ & $\mathrm{T} 1(\mathrm{n}=8) ; \mathrm{T} 2(\mathrm{n}=5)$ \\
\hline Embryonal carcinoma & $\mathrm{N}=0$ & & $\mathrm{~N}=8^{\mathrm{c}}$ & $\mathrm{T} 1(\mathrm{n}=6) ; \mathrm{T} 2(\mathrm{n}=2)$ \\
\hline Yolk sac tumor & $\mathrm{N}=0$ & & $\mathrm{~N}=4^{\mathrm{c}}$ & $\mathrm{T} 1(\mathrm{n}=4)$ \\
\hline Immature teratoma & $\mathrm{N}=0$ & & $\mathrm{~N}=1^{\mathrm{c}}$ & $\mathrm{T} 1(\mathrm{n}=1)$ \\
\hline \multicolumn{5}{|l|}{ Sex cord stromal tumors } \\
\hline Juvenile granulosa cell tumor & $\mathrm{N}=1$ & IA & $\mathrm{N}=3$ & $\mathrm{~T} 1(\mathrm{n}=3)$ \\
\hline Adult granulosa cell tumor & $\mathrm{N}=5$ & IA & $\mathrm{N}=0$ & \\
\hline Sertoli cell tumor & & & $\mathrm{N}=3$ & $\mathrm{~T} 2 \mathrm{~N} \times \mathrm{M} 1(\mathrm{n}=2), \mathrm{T} 1(\mathrm{n}=1)$ \\
\hline (Sertoli-Leydig cell tumor in the ovary) & $\mathrm{N}=3$ & IA & & \\
\hline Fibro-thecoma & $\mathrm{N}=3$ & IA & $\mathrm{N}=0$ & \\
\hline Leydig cell tumor & $\mathrm{N}=3$ & IA & $\mathrm{N}=4$ & $\mathrm{~T} 1(\mathrm{n}=4)$ \\
\hline Total & $\mathrm{N}=15$ & & $\mathrm{~N}=36$ & \\
\hline
\end{tabular}

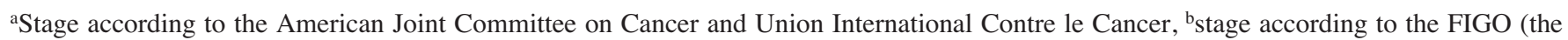
International Federation of Gynecology and Obstetrics), 'tumors with available frozen material, for which RT-PCR was performed.

gonadal stromal and germ cell tumors, in order to answer the following questions: i) Is galectin-3 absent from normal germ cells and present in germ cell tumors, indicating the possible implication of this lectin in germ cell tumorigenesis? ii) Is galectin-3 a marker of Sertoli cells in human testis? iii) What is the pattern of expression of this lectin in sex cord gonadal stromal tumors and can it be helpful in distinguishing testicular and ovarian Sertoli cell tumors from other sex cord stromal tumors such as granulosa cell tumors?

\section{Materials and methods}

Immunohistochemistry. A total of seven normal human testes at different stages of development, including testes from fetuses at $8,20,25,30$, and 31 weeks of gestation (provided by autopsy material after miscarriages and termination of pregnancies for medical purposes), one year-old child (normal tissue adjacent to a testicular hematoma), and adult (provided from orchidectomy in a patient with prostatic cancer), two cryptorchid testes (one with Sertoli cell only tubules and one with Sertoli cell nodules), one normal adult ovarian parenchyma, and 25 gonadal neoplasms (10 testicular and 15 ovarian tumors), were retrieved from the files of the Departments of Pathology at Croix Rousse and Edouard Herriot Hospitals, Lyon, France (Table I). All tissues were Bouin fixed and paraffin embedded. H\&E and saffron-stained slides were reviewed, and one representative tissue section from each case was selected for immunohistochemical analysis. Six micron sections were deparaffinized and rehydrated through graded alcohols to water. The slides were immersed in $10 \mathrm{mmol} / \mathrm{l}$ citrate buffer, $\mathrm{pH} 6.0$ and subjected to heatinduced antigen retrieval for pretreatment. For each case, mouse monoclonal antibody to human galectin-3 (clone NCL-Gal 3, diluted at 1/150, Novocastra, USA) and mouse monoclonal antibody to human androgen receptors (clone AR441, diluted at 1/50, Dako, Grenoble, France) were applied. Immunodetection was performed using the two-step peroxidase technique (Envision +, Dako Corporation). Negative controls were performed omitting the primary antibody. The intensity of the staining was determined as weak $(+)$, moderate $(++)$ or strong $(+++)$.

Quantitative real-time RT-PCR. A total of 26 testicular germ cell tumors (Table I) and two non-neoplastic testicular tissues for which frozen material was available, were analyzed. For each case, a fragment was snap-frozen after the surgery and stored at $-80^{\circ} \mathrm{C}$. Each frozen fragment was verified histologically and samples that did not contain more than $80 \%$ non-necrotic tumor cells were excluded from the study. In addition, two pure human cell lines were analyzed. The JKT-1 cell line, a pure human seminoma cell line was kindly provided by P Fenichel (8) and the NCCIT cell line, a pure human non-seminomatous cell line (embryonal carcinoma) was kindly provided by E Tabone (9). Total RNA was extracted by using TRIzol Reagent according to the manufacturer's instructions (Life Technologies, France). We reverse-transcribed $1 \mu \mathrm{g}$ of total RNA in a total volume of $20 \mu \mathrm{l}$ during $1 \mathrm{~h}$ at $37^{\circ} \mathrm{C}$ using Moloney murine leukemia virus reverse transcriptase $(200 \mathrm{U} / \mu \mathrm{l})$, random primers $(50 \mu \mathrm{M})$, dNTPs $(200 \mu \mathrm{M})$ and dithiothreitol $(100 \mathrm{mM})$. SYBR-Green realtime PCR assays were carried out using the QuantiTect SYBR-Green PCR kit (Qiagen S.A, France), as previously described (10). The primers used were as follows: galectin-3, 5'-CAgCCAAgTgCCACCg-3' and 5'-AAACCgACTgT CTTTCTTCCC-3'; $B$-actin (11). The amount of galectin-3 relative to the amount of $\beta$-actin in the same sample was analyzed by the relative quantification approach with the use of efficiency correction using Real Quant 1.0 software (Roche Molecular Biochemicals).

Data analysis. For statistical analysis, one way analysis of variance (ANOVA) was performed to determine whether 
Table II. Immunohistochemical results with anti-galectin-3 and anti-androgen receptor.

Specimen

Galectin-3

Androgen receptor

Ovary

Normal adult ovary

Granulosa and theca cells

Surface epithelium

Stroma

$+++$

$+$

$0 / 15$

Sex cord stromal tumors

Testis

Fetuses at different ages

Sertoli cells

Germ cells

Leydig cells

Pre-pubertal (normal testis)

Sertoli cells

Germ cells

Leydig cells

Adult (normal testis)

Sertoli cells

Germ cells

Leydig cells

$+++$

$-$

$++$

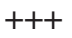

$-$

Immature Sertoli cell nodules

Sex cord stromal tumors

Leydig cell tumors $\quad 4 / 4$

Sertoli cell tumors $\quad 0 / 3$

Juvenile granulosa cell tumors $\quad 0 / 3$

$0 / 13$ (+ in stromal macrophages)

NA

Seminoma

Embryonal carcinoma

$0 / 8$

Yolk sac tumor

Immature teratoma

NA, not assessed; (+/++/+++), low/moderate/high intensity of immunostaining.

there were differences between all groups $(\mathrm{p}<0.05)$, and then Fisher's post-test was performed to determine the significance of the differences between the pair of groups. A P-value $<0.05$ was considered significant. The statistical tests were performed on StatView software version 5.0 (SAS institute Inc, Cary, NC).

\section{Results}

Galectin-3 expression in non-neoplastic gonads and sex cord stromal tumors using immunohistochemistry. In all fetal testes at different ages $(8,20,25,30$ and 31 weeks of amenorrhea) and in normal testis before puberty, no immunostaining with anti-galectin-3 antibody was detected (Fig. 1A and B). In contrast, in post-pubertal normal testicular parenchyma, strong and diffuse cytoplasmic staining was seen in all Sertoli cells (Fig. 1C). Weak cytoplasmic positivity was also detected in a few Leydig cells.

In cryptorchid testes, the Sertoli cell only tubes showed diffuse and strong cytoplasmic staining (Fig. 1E). In contrast, in Sertoli cell nodules, the immature-appearing Sertoli cells were negative, while mature Sertoli cells displayed the same pattern of staining to that of Sertoli cells in eutrophic testicular parenchyma (Fig. 1F).

In contrast to normal mature Sertoli cells, none of the other sex cord stromal tumors including three juvenile granulosa cell tumors and three Sertoli cell tumors expressed galectin-3.

Galectin-3 protein expression was down-regulated in testicular Sertoli cell tumors, while Leydig cell tumors expressed the protein (Table II, Fig. 1D and G). 

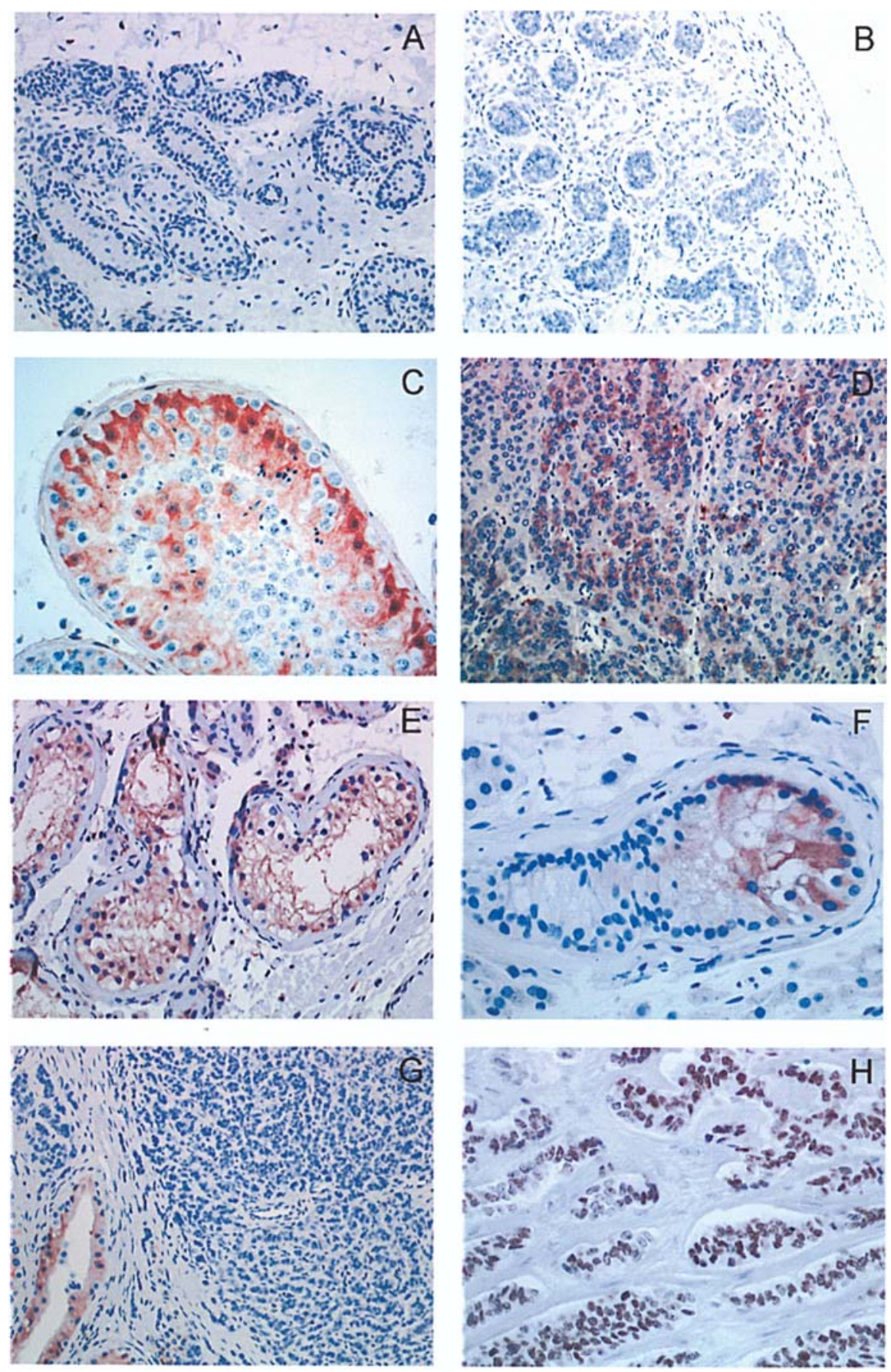

Figure 1. Immunohistochemical study. (A) Lack of galectin-3 expression in post-natal testis (one year-old) (immunoperoxidase x400). (B) Lack of galectin-3 expression in fetal testis (31 weeks of amenorrhea) (immunoperoxidase $\mathrm{x} 400$ ). (C) Galectin-3 expression in adult testis (immunoperoxidase $\mathrm{x} 400$ ): Cytoplasmic staining in mature Sertoli cells, without staining of germ cells. (D) Benign testicular Leydig cell tumor with preserved galectin-3 expression (immunoperoxidase x400). (E) Galectin-3 cytoplasmic expression in Sertoli cell only tubules of cryptorchid testis (immunoperoxidase x400). (F) In Sertoli cell nodules of a cryptorchid testis, only mature Sertoli cells were positive, while immature Sertoli cells within the same seminiferous tubule lost galectin-3 expression (immunoperoxidase $\mathrm{x} 400$ ). (G) Malignant testicular Sertoli cell tumor showing a loss of galectin-3 expression with residual seminiferous tubules showing immunoreactivity in mature Sertoli cells (immunoperoxidase x200). (H) Testicular Sertoli cell tumor demonstrating nuclear immunostaining with antiandrogen receptor antibody (immunoperoxidase x200).

The protein was not expressed in either granulosa cells or sex cord stromal tumors in the ovaries (Table II). The only component strongly and diffusely expressing the protein in normal ovaries was the surface epithelium.

Androgen receptors $(A R)$. In order to determine the variation of galectin-3 expression in testes according to the hormonal status, we carried out an immunohistochemical study using
anti-AR antibody. Nuclear staining was observed in mature Sertoli cells and in testicular sex cord stromal tumors (Table II, Fig. $1 \mathrm{H})$.

Galectin-3 expression in testicular germ cell tumors and cell lines. Galectin-3 mRNA expression was determined by realtime PCR in 26 testicular germ cell tumors. Seminomas expressed galectin-3 (median galectin-3/actin mRNA concen- 


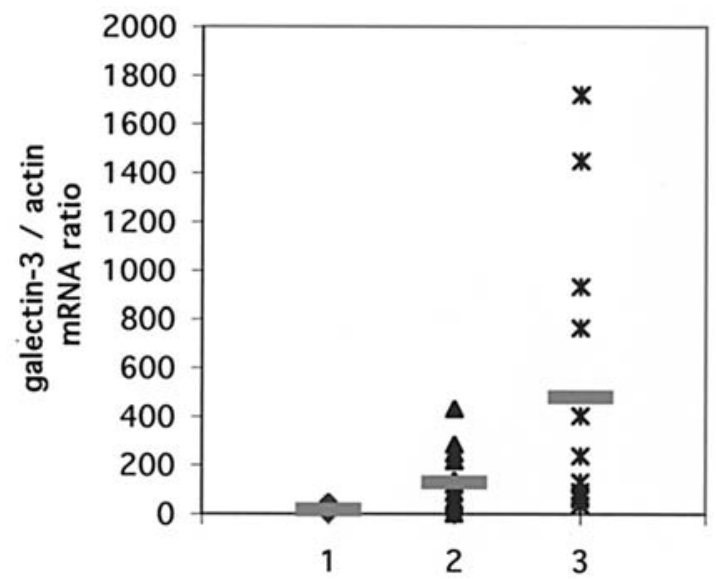

Figure 2. Galectin-3 mRNA expression in testicular germ cell tumors using real-time PCR. (1) Normal adult testis. (2) Seminomas. (3) Non-seminomas. The grey bar indicates the mean value.

tration ratio $=129)$, but no significant difference $(\mathrm{p}=0.6051)$ was observed as compared to non-neoplastic testicular tissue (median galectin-3/actin mRNA concentration ratio $=15.97$ ) (Fig. 2).

By contrast, a significant increase in galectin-3 mRNA expression was observed in non-seminomatous tumors (median galectin-3/actin mRNA concentration ratio $=477.5$ ) as compared to normal testes $(\mathrm{p}=0.0432)$ and to seminomas $(\mathrm{p}=0.0247)$. However, galectin-3 mRNA expression did not correlate with tumor stage (T1 versus $\mathrm{T} 2$ ).

The difference of expression between seminomas and nonseminomas was confirmed using two cell lines representing the two histological subtypes of germ cell tumors. Indeed, galectin-3 mRNA expression was higher in the non-seminomatous cell line (NCCIT) as compared to the seminoma cell line (JKT-1) (median galectin-3/actin mRNA concentration ratio of 1590 and 462, respectively) (Fig. 3).

\section{Discussion}

The data presented herein show that galectin-3 is a specific marker of human mature Sertoli cells. The ontogeny of galectin-3 expression was studied in human testes from fetuses at different ages, in pre-pubertal and post-pubertal testes. This protein is absent from fetal and pre-pubertal testes and ovarian granulosa cells, and appears in post-pubertal testicular parenchyma, in Sertoli and Leydig cells, without expression in germ cells. In the mouse embryo, galectin-3 is absent from developing testes, consistent with our findings in human fetuses at different ages (12). Interestingly, galectin-3 is present in the cytoplasm of mature Sertoli cells in adult testes as previously reported (5). The variation in galectin-3 expression in the testis according to the degree of cell maturation and differentiation might be related to the hormone dependence of galectin genes, since galectin-3 appears in mature and differentiated androgen-sensitive Sertoli cells. Hormone regulation of galectin-3 expression has been suggested in steroid-sensitive breast carcinoma cells (13). We have recently demonstrated the hormonal regulation of galectin-3 expression in porcine Sertoli cells, with a possible link between galectin-3 expression

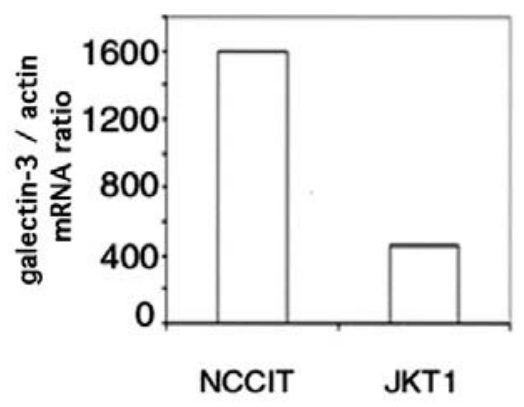

Figure 3. Galectin-3 mRNA expression in human germ cell tumor cell lines using real-time PCR. (JKT-1) Seminoma cell line. (NCCIT) Non-seminoma cell line.

and the follicular stimulating hormone (FSH) (unpublished data). In our study, the expression of galectin-3 protein in normal testes correlated with the degree of maturation and differentiation of cells. Galectin-3 expression was superimposed on that of androgen receptors, as confirmed in Sertoli cell nodules of cryptorchid testes, where immature appearing Sertoli cells lose their AR immunoreactivity, and also their galectin-3 expression.

Another interesting finding of our study was the variation of galectin-3 expression in human testicular tumors according to the histological type of tumors, and their hormone dependency. The gene was expressed by non-neoplastic sex cord cells (i.e. Sertoli and Leydig cells) and was down-regulated in Sertoli cell tumors, while Leydig cell tumors continued to express the protein. On the other hand, the gene was absent from nonneoplastic spermatogonia and was up-regulated in testicular germ cell tumors, specifically in the non-seminomatous subtypes. The expression of galectin-3 has been reported to vary depending on the type of tumor and tissue, and in a given tumor in relation to the stage of the disease (14). It has been shown in vitro that a decrease in galectin-3 synthesis is associated with acquisition of contact inhibition, reduction of serum independence, and abrogation of anchorage-independent cell growth (15). Thus, in our study, down-regulation of galectin-3 in testicular Sertoli cell tumors, two of which were malignant and associated with lung metastasis, may be related to the tumorigenesis and progression of these neoplasms. In contrast, galectin-3 protein was expressed in Leydig cell tumors, all of which had a benign behavior. We have shown that galectin-3 is a potentially hormone-dependent gene (unpublished data) and it is worth noting that the expression of galectin-3 is up-regulated in the majority of malignancies such as thyroid (2) and pancreatic (3) tumors, and is downregulated in steroid hormone-dependent tumors such as breast (15), ovarian (16), prostatic (17) carcinomas, and also in Sertoli cell tumors as demonstrated herein. Sex cord gonadal stromal tumors are thought to be derived from undifferentiated sex cords in both the ovaries and testes. The lack of galectin-3 expression in these tumors might either reflect the histogenesis of these tumors or their tumorigenesis. We demonstrated that immature Sertoli cells do not express this gene. Since AR protein is detected in these tumors and is absent from immature Sertoli cells and undifferentiated sex cords, we suggest that the lack of galectin-3 in testicular Sertoli cell tumors is related to their tumorigenesis and tumor progression rather than their 
histogenesis. Although galectin-3 expression can differentiate mature Sertoli cells from granulosa cells, it is not a useful marker in distinguishing Sertoli and Sertoli-Leydig cell from granulosa cell tumors, since the protein is absent from both types of neoplasms in the testes as well as in the ovaries.

We have seen expression of the galectin-3 messenger in testicular germ cell tumors, while the protein is absent from non-neoplastic spermatogonia from which these tumors are thought to derive. Although no significant difference of expression was seen between seminomas and non-neoplastic testes, a significantly higher messenger expression of galectin-3 was observed in non-seminomas, as compared to seminomas and non-neoplastic testes. In accordance with our results, the increased expression of lectins has been reported in nonseminomatous testicular germ cell tumors (18). However, the type of lectin involved was not determined. Galectin-3 protein has been detected in $60 \%$ of testicular germ cell tumors $(16,27)$ using immunohistochemistry with a polyclonal antibody, but the results did not correlate with the histological type of positive tumors (seminomas vs non-seminomas) (6). It has been suggested that RT-PCR alone is not a reliable method for the evaluation of galectin-3 expression, because macrophages and activated endothelial cells express galectin3 (19). To confirm that galectin-3 mRNA is indeed present in tumor cells and is not due to the presence of macrophages in the stroma of germ cell tumors, we performed real-time PCR analysis on two pure human cell lines from a seminoma (JKT-1) (8) and a non-seminoma (NCCIT) (9). Both cell lines expressed galectin-3. Moreover, pure non-seminomatous cells showed a three-times higher level of galectin-3 mRNA expression than seminoma cells, confirming our findings on human tumor tissues. Our results on cell lines and tumoral tissue show that galectin-3 expression is significantly higher in the more aggressive subtype of testicular germ cell tumor (i.e. non-seminomas). Thus, the more aggressive behavior of non-seminomas might be, in part, explained by the antiapoptotic and the proliferative activities of galectin-3. Indeed, the antiapoptotic activity of this protein has been suggested to explain its carcinogenetic implication. This antiapoptotic activity may be due to the similarity between galectin-3 and $\mathrm{Bcl}-2$ protein, and the capability of this lectin to replace or mimic Bcl-2 protein, blocking the release of cytochrome $\mathrm{C}$ from the mitochondria (20). It has been demonstrated that the overexpression of galectin-3 in bladder cancer cells rendered them resistant to TRAIL-induced apoptosis by involving Akt as a modulator molecule (21).

In summary, our data show that galectin-3 is a marker of mature Sertoli cells that might be implicated in Sertoli cell functions. Galectin-3 is a marker of aggressiveness in testicular tumors. While the gene is down-regulated in malignant Sertoli cell tumors, it is up-regulated in non-seminomatous testicular germ cell tumors. These data indicate the role of this lectin in malignant sex cord gonadal stromal tumorigenesis and in the non-seminomatous differentiation of germ cell tumors.

\section{Acknowledgements}

This work is supported by la Ligue régionale contre le cancer (Départements de l'Ain, du Rhône et de l'Ardèche) (MD-S), INSERM and Université Claude Bernard, Lyon I.

\section{References}

1. Krzeslak A and Lipinska A: Galectin-3 as a multifunctional protein. Cell Mol Biol Lett 9: 305-328, 2004.

2. Xu XC, el-Naggar AK and Lotan R: Differential expression of galectin-1 and galectin-3 in thyroid tumors. Potential diagnostic implications. Am J Pathol 147: 815-822, 1995.

3. Berberat PO, Friess H, Wang L, Zhu Z, Bley T, Frigeri L, Zimmermann A and Buchler MW: Comparative analysis of galectins in primary tumors and tumor metastasis in human pancreatic cancer. J Histochem Cytochem 49: 539-549, 2001.

4. Song YK, Billiar TR and Lee YJ: Role of galectin-3 in breast cancer metastasis: involvement of nitric oxide. Am J Pathol 160: 1069-1075, 2002.

5. Wollina U, Schreiber G, Gornig M, Feldrappe S, Burchert M and Gabius HJ: Sertoli cell expression of galectin-1 and -3 and accessible binding sites in normal human testis and Sertoli cell only-syndrome. Histol Histopathol 14: 779-784, 1999.

6. Kayser K, Hoeft D, Hufnagi P, Caselitz J, Zick Y, Andre S, Kaltner $\mathrm{H}$ and Gabius HJ: Combined analysis of tumor growth pattern and expression of endogenous lectins as a prognostic tool in primary testicular cancer and its lung metastases. Histol Histopathol 18: 771-779, 2003.

7. Young RH: Sex cord-stromal tumors of the ovary and testis: their similarities and differences with consideration of selected problems. Mod Pathol 18 (suppl 2): 81-98, 2005.

8. Kinugawa K, Hyodo F, Matsuki T, Jo Y, Furukawa Y, Ueki A and Tanaka H: Establishment and characterization of a new human testicular seminoma cell line, JKT-1. Int J Urol 5: 282-287, 1998.

9. Andjilani M, Droz JP, Benahmed M and Tabone E: alpha6 integrin subunit mediates laminin enhancement of cisplatin-induced apoptosis in testicular tumor germ cells. Int J Cancer 117: 68-81, 2005.

10. Bozec A, Ruffion A, Decaussin M, Andre J, Devonec M, Benahmed M and Mauduit C: Activation of caspases-3, -6, and -9 during finasteride treatment of benign prostatic hyperplasia. J Clin Endocrinol Metab 90: 17-25, 2005.

11. Kreuzer KA, Lassu U, Landt O, et al: Highly sensitive and specific fluorescence reverse transcription-PCR assay for the pseudogene-free detection of beta-actin transcripts as quantitative reference. Clin Chem 45: 297-300, 1999.

12. Fowlis D, Colnot C, Ripoche MA and Poirier F: Galectin-3 is expressed in the notochord, developing bones, and skin of the postimplantation mouse embryo. Dev Dyn 203: 241-251, 1995.

13. Van den Brule FA, Engel J, Stetler-Stevenson WG, Liu FT, Sobel ME and Castronovo V: Genes involved in tumor invasion and metastasis are differentially modulated by estradiol and progestin in human breast-cancer cells. Int J Cancer 52: 653-657, 1992.

14. Chiariotti L, Salvatore P, Frunzio R and Bruni CB: Galectin genes: regulation of expression. Glycoconj J 19: 441-449, 2004.

15. Honjo Y, Nangia-Makker P, Inohara $\mathrm{H}$ and Raz A: Downregulation of galectin-3 suppresses tumorigenicity of human breast carcinoma cells. Clin Cancer Res 7: 661-668, 2001.

16. Van den Brule FA, Berchuck A, Bast RC, Liu FT, Gillet C, Sobel ME and Castronovo V: Differential expression of the 67$\mathrm{kD}$ laminin receptor and 31-kD human laminin-binding protein in human ovarian carcinomas. Eur J Cancer 30A: 1096-1099, 1994.

17. Pacis RA, Pilat MJ, Pienta KJ, Wojno K, Raz A, Hogan V and Cooper CR: Decreased galectin-3 expression in prostate cancer. Prostate 44: 118-123, 2000.

18. Gabius HJ, Engelhardt R, Casper J, Schmoll HJ, Nagel GA and Cramer F: Comparison of endogenous lectins in human embryonic carcinoma and yolk sac carcinoma. Tumour Biol 6: 471-482, 1986.

19. Bartolazzi A, Gasbarri A, Papotti M, Bussolati G, Lucante T, Khan A, Inohara H, Marandino F, Orlandi F, Nardi F, Vecchione A, Tecce R and Larsson O: Thyroid Cancer Study Group. Application of an immunodiagnostic method for improving preoperative diagnosis of nodular thyroid lesions. Lancet 357: 1644-1650, 2001.

20. Matarrese P, Tinari N, Semeraro ML, Natoli C, Iacobelli S and Malorni W: Galectin-3 overexpression protects from cell damage and death by influencing mitochondrial homeostasis. FEBS Lett 473: 311-315, 2000.

21. Oka N, Nakahara S, Takenaka Y, et al: Galectin-3 inhibits tumor necrosis factor-related apoptosis-inducing ligand-induced apoptosis by activating Akt in human bladder carcinoma cells. Cancer Res 65: 7546-7553, 2005. 